\title{
SNAPSHOT
}

\section{Water, water not everywhere}

The first half of 2021 has seen drought on most continents. Regions receiving the most coverage are the western US and Canada, but regional drought has cropped up in other places (see map of surface soil moisture in June 2021, with lower values in darker red).

Further south, Mexico and Brazil are experiencing one of the worst water crises in almost a century. For Mexico, this is driven by increased water consumption during 2020, owing to more residential water use during COVID-19 and increased agricultural production. Brazil has experienced below-average rain for the past decade, resulting in depleted water throughout the Panará River Basin, which serves five states and is home to hydroelectric dams. The hydroelectric power impacts have inflated electricity bills and carry a threat of power rationing, made politically complicated with presidential elections on the horizon.

"Drought has become more frequent and intense throughout Brazil in recent years," says Ana Paula Cunha of the National Center for Monitoring and Early Warning of Natural Disasters (CEMADEN) in São Paulo, Brazil, adding that these extremes are part of a new normal. "Impacts vary regionally due to the country's socioeconomic inequalities. In the semiarid northeast, drought mainly affects smallholder families relying on subsistence agriculture. In central and southern Brazil, it affects large-scale agriculture and energy generation." Regional warming trends exacerbate these impacts, explains Cunha, since reduced rainwater causes increased evaporative demand and reduces reservoir inflows.

Drought is also threatening food security in Central Asia and Madagascar. In arid regions of Central Asia, populations are accustomed to low groundwater and river levels, but below-average rainfall and higher temperatures in recent years have exacerbated this deficit. Crop failure and widespread livestock death are already underway, and the toll is expected to worsen in the coming months. This is particularly felt in countries like Uzbekistan and Kazakhstan, which rely on the Amu Darya and Syr Darya rivers originating upstream in the mountains of Tajikistan and Kyrgyzstan. Climate change shifts the melt season earlier in mountain regions, and low precipitation intensifies these issues; downstream

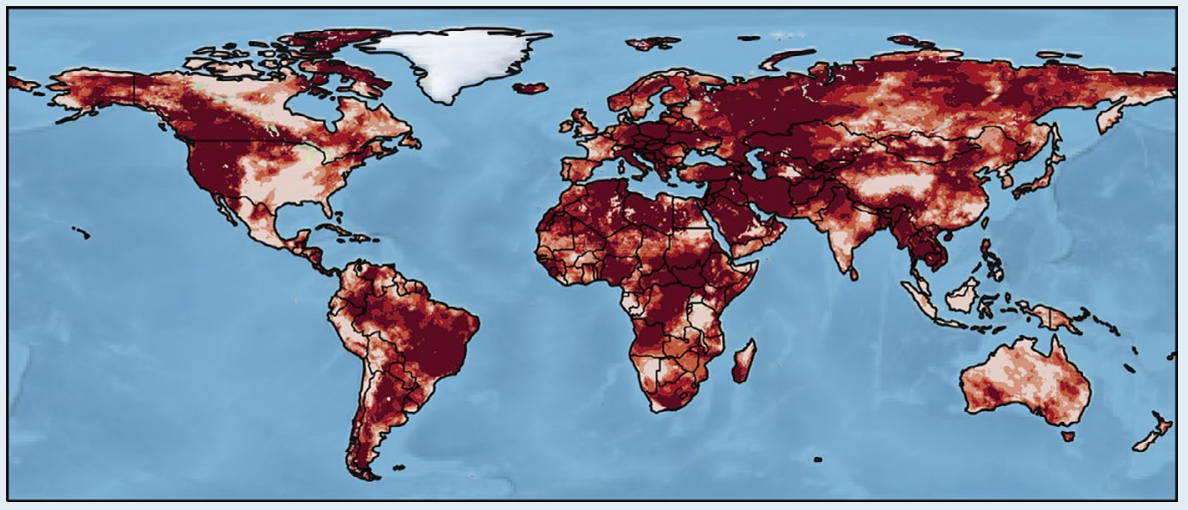

Credit: Data courtesy of https://nasagrace.unl.edu/globaldata/current/

neighbours are now at a disadvantage, and quid pro quo agreements are springing up that trade water for machinery and fuel.

In southern Madagascar, low rainfall during the last two planting seasons caused consecutive failed harvests, as farmers relying on traditional planting methods lost seeds. This is not uncommon for the region. "Southern Madagascar has been affected by severe drought six times in the last decade, often with total loss of crops and widespread food insecurity", says Francois Kayitakire of African Risk Capacity (ARC) in Johannesburg, South Africa. Current aridity, accompanied by soil erosion and deforestation, leaves the region vulnerable to sandstorms that turn croplands and pasture to wasteland. An extended lean season the window between harvests when rainfall is limited and inhabitants rely on alternative sources of food, like cactus fruit - is aggravating these losses. Now, nearly 1.35 million people are in a state of acute food insecurity and need emergency assistance, complicated by COVID-19's impacts on emergency services and food prices.

Drought early warning systems and methods of modern cash transfer are ways to get ahead of these disasters. For Brazil, CEMADEN has been monitoring drought conditions since 2013 and performing drought forecasts and scenarios, explains Cunha. In southern Madagascar, systems like ARC's African Risk View can detect early signs of a failed crop season, and insurance mechanisms can anticipate these impacts. In May 2020, for example, Madagascar received US\$2.13 million through ARC to provide early support to the most affected households. "However, the current levels of drought risk coverage are not sufficient", Kayitakire explains. "Expanded risk insurance and other financing mechanisms like contingent credit are needed to manage the entire spectrum of risk."

These droughts are examples of compound events worsening with climate change. "The probability of simultaneous drought across multiple regions is increasing", explains Franziska Gaupp of the International Institute for Applied Systems Analysis in Laxenburg, Austria. "Concurrent crop losses in major production regions can cause price spikes and have cascading effects on food access, famine and food riots." Gaupp reiterates the need for early warning systems and financing mechanisms.

"Ex-ante (forecast-based) cash transfers can stabilize livelihoods and prevent food price crises, and these are more cost-effective than ex-post disaster relief."

Anticipating these crises therefore relies on well-designed financing mechanisms coupled with intelligent forecasting systems. "We need to take a systems perspective rather than a siloed approach", Gaupp says. "Drought needs to been seen as more than a biophysical hazard and include socioeconomic vulnerabilities, coping capacities and exposure."

\section{Baird Langenbrunner}

Published online: 5 August 2021

https://doi.org/10.1038/s41558-021-01111-9 